\title{
Precursores da cromatografia gás-sólido
}

\author{
Carol Hollingworth Collins \\ Instituto de Química, Universidade Estadual de Campinas - UNICAMP \\ Cep 13083-970, Campinas, SP, Brasil \\ e-mail: chc@iqm.unicamp.br
}

Resumo

A adsorção de gases em carvão pulverizado foi descrita no século XIX, sem ser aplicada para fins de identificação ou quantificação. Entretanto, estudos no início do século XX começaram a fazer determinações qualitativas e, eventualmente, quantitativas dos conteúdos de misturas de gases em sistemas cromatográficos, aplicando diversos sólidos, com desenvolvimento por deslocamento ou por análise frontal. Algumas dessas contribuições estão descritas para ilustrar os antecedentes da cromatografia gasosa.

Palavras-chave

História da cromatografia; cromatografia gasosa; cromatografia gás-sólido; mecanismo de adsorção.

\section{Precursors of gas-solid chromatography}

\section{Abstract}

Adsorption of gases onto powdered charcoal was described in the $19^{\text {th }}$ century, without being applied for identification or quantification. However, studies at the start of the $20^{\text {th }}$ century began to make qualitative and, eventually, quantitative determinations of the contents of mixtures of gases in chromatographic systems, applying development by displacement or by frontal analysis. Some of these contributions are described here, to illustrate the antecedents of gas chromatography.

Keywords

History of chromatography; gas chromatography; gás-solid chromatography; adsorption mechanism. 
Diferentemente da cromatografia líquido-sólido realizada em coluna aberta e as cromatografias planares, assuntos dos capítulos anteriores, o uso de gás como amostra ou fase móvel requisitava sistema fechado. Tais sistemas foram construídos, no início do século dezenove e usados para estudar a adsorção de gases em sólidos, sem a intenção de avaliar possíveis separações.

Por exemplo, em 1819, Gmelin (apud Wintermeyer ${ }^{[1]}$ ) relatou que diversas substâncias, entre elas os gases, eram "consumidas" por carvão vegetal em quantidades diferentes, mas poderiam ser removidas com água ou com calor. Ele indicou que o carvão tinha uma alta afinidade para várias substâncias odoríferas, incluindo fumo de tabaco e compostos sulfurosos emitidos por algumas águas. Neste mesmo trabalho, ele também descreveu o uso destes carvões para descolorir vinho tinto e soluções ácidas de índigo.

No ano de 1833, Schwarte (apud Wintermeyer ${ }^{[1]}$ ), no seu livro texto Pharmakologischen Tabellen, indicou que o carvão vegetal tinha a capacidade de adsorver quantidades significativas de diversos gases postos em contato com seus poros, o que permitia concentrá-los, indicando que outras substâncias porosas também apresentavam esta propriedade.

O trabalho do dr. W. Ramsey ${ }^{[2]}$, publicado em 1905, descreveu a análise de misturas de gases utilizando carvão vegetal mantido em diferentes temperaturas. Quando se passava ar através de um tubo recheado com um pó de carvão resfriado a $-100{ }^{\circ} \mathrm{C}$, nitrogênio, oxigênio e argônio eram adsorvidos. O restante ia para a parte do tubo resfriada a $-196^{\circ} \mathrm{C}$, onde neônio era retido, deixando o hélio sair. Após o que as diferentes partes do tubo eram aquecidas, permitindo a saída dos demais gases.

O primeiro trabalho considerado um processo cromatográfico foi o de Berl e Schmidt ${ }^{[3]}$, do Instituto de Engenharia Química da
Universidade Técnica de Darmstadt, publicado em 1923. No sistema experimental mais simples (Figura 1), uma amostra de gases foi colocada em um recipiente fechado contendo água ou benzeno. Esse tubo foi conectado a um tubo recheado com carvão vegetal ativado em um banho de óleo, o que permitiu seu aquecimento. O tubo com a amostra foi aquecido e os vapores do líquido empurraram a amostra até a coluna, onde os seus constituintes foram adsorvidos e, com o aumento da temperatura ao redor do tubo de carvão, dessorvidos, sendo os volumes dos gases medidos por um gasômetro. $\mathrm{O}$ processo de desenvolvimento foi, principalmente, deslocamento pelo líquido em ebulição, assistido por dessorção térmica.

O sistema mais sofisticado de Berl e Schmidt ${ }^{[3]}$ (Figura 2) utilizou um interferômetro de gases como detector. A amostra foi colocada em um frasco grande, conectado por um tubo a um frasco similar contendo água. A passagem da água do seu reservatório para o frasco contendo a amostra empurrava a amostra continuamente na direção da coluna, passando por um medidor de fluxo e um tubo contendo cloreto de cálcio, para secagem dos gases. Antes de entrar na coluna, a mistura de gases passava por um lado do interferômetro. Depois de passar através da coluna recheada com carvão ativado, que poderia ou não ter sua temperatura controlada, o efluente passava para o segundo lado do interferômetro, sendo a diferença nas medidas utilizada para construir um cromatograma em função do volume de gases que saiam do aparelho. A coluna poderia ser aquecida, dependendo da composição da mistura em estudo. Como pode-se notar na Figura 3, a composição dos gases que saem variou, sendo que a primeira parte (mais para a esquerda) representa o valor do primeiro componente da mistura, puro. A segunda porção representa uma mistura do primeiro componente (menos retido) com o segundo menos 


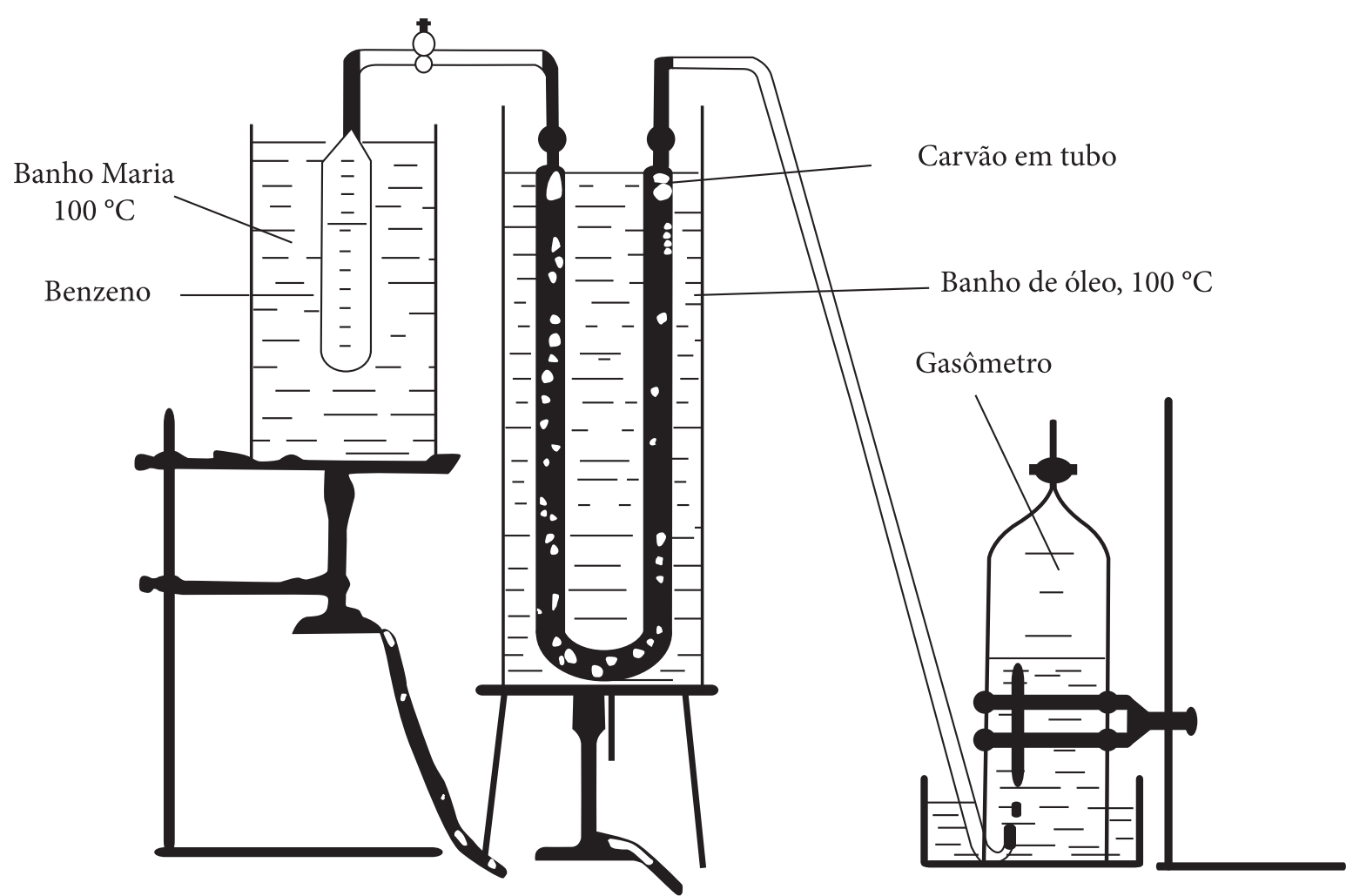

Figura 1 Equipamento simples de Berl e Schmidt para a dessorção de gases e vapores (modificada da referência 3).

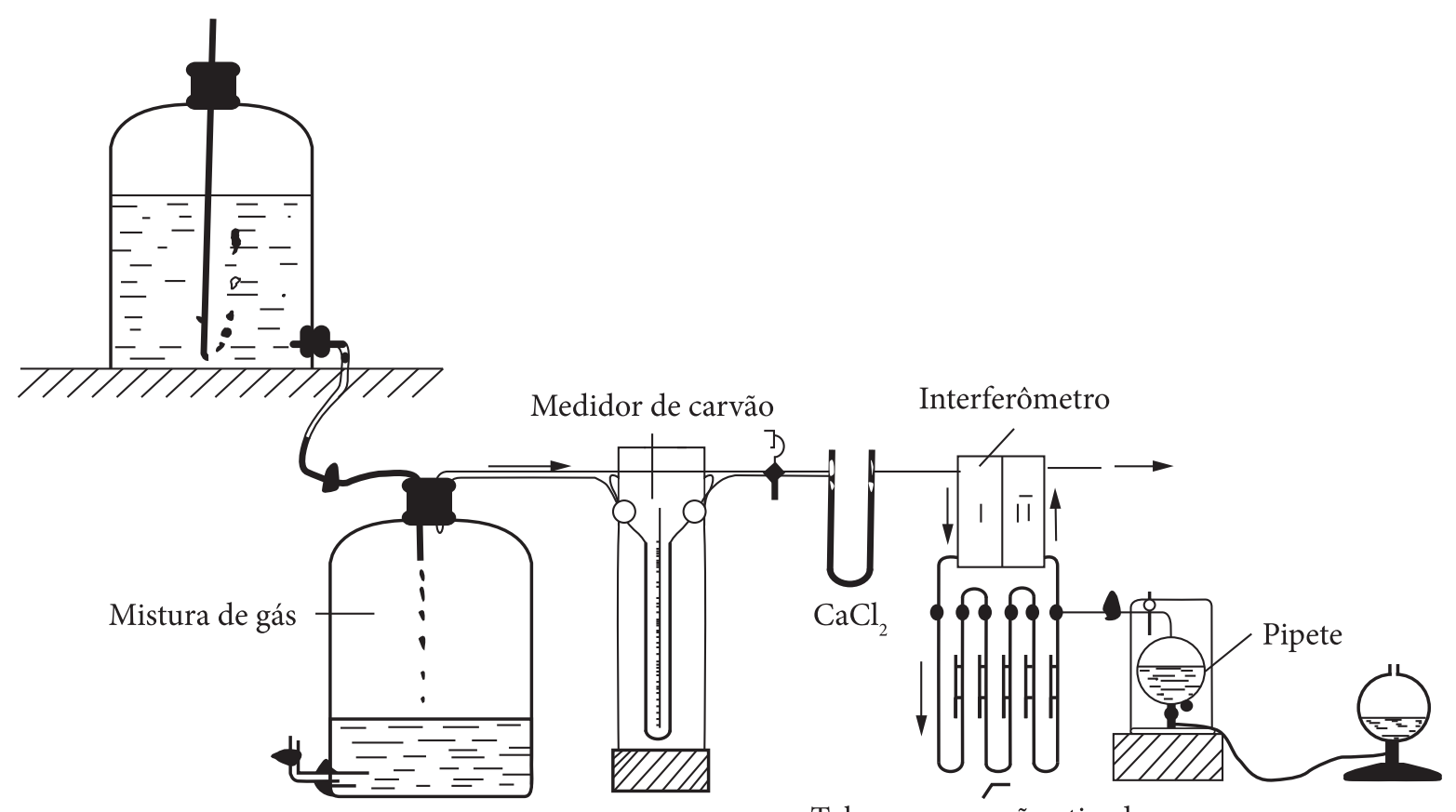

Tubos com carvão ativado

Figura 2 Equipamento de Berl e Schmidt para análise frontal de gases e vapores (modificada da referência 3). 


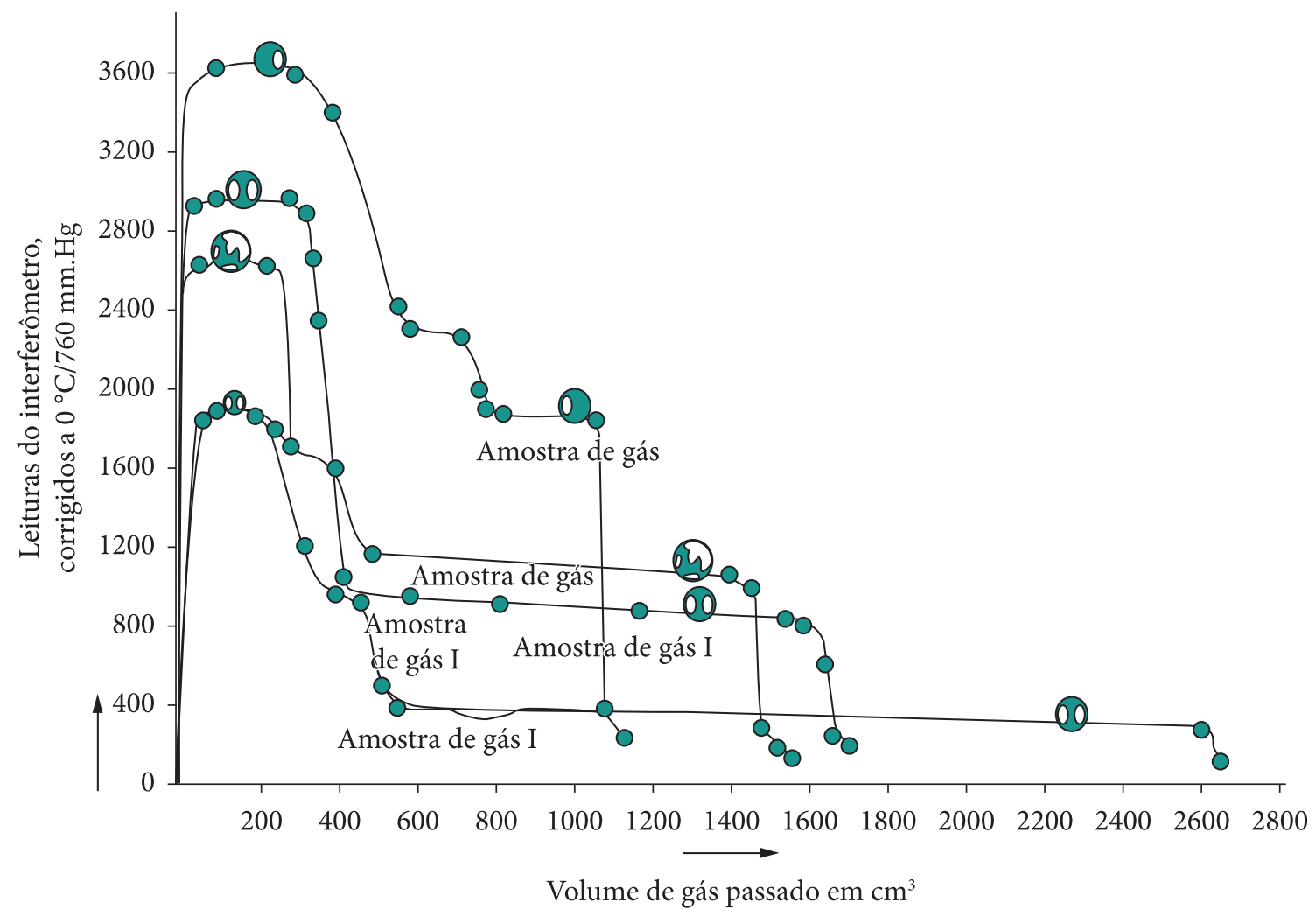

Figura 3 Cromatogramas desenvolvidos por análise frontal por Berl e Schmidt (modificada da referência 3).

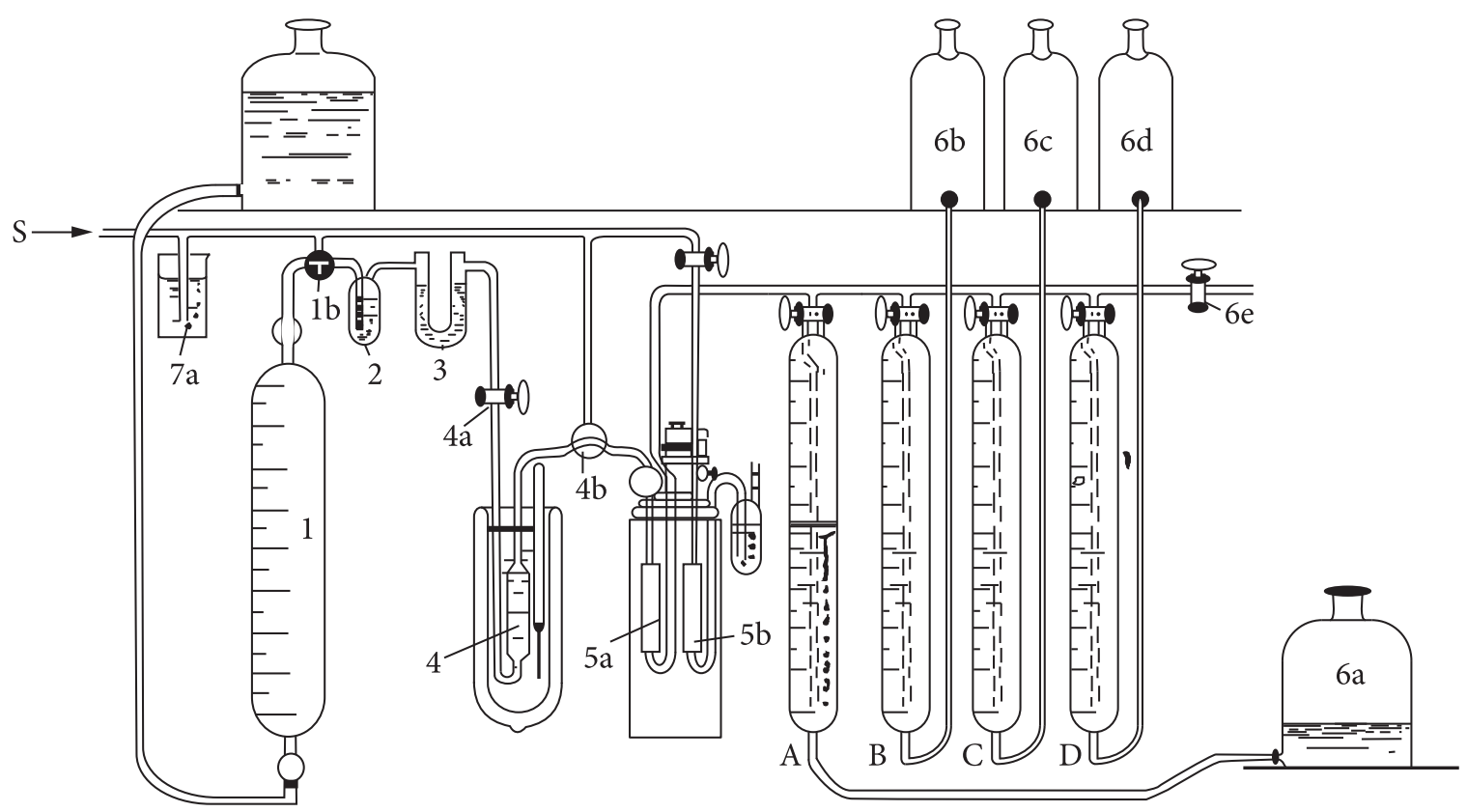

Figura 4 Equipamento de Schuftan para a análise de gases e vapores. $\mathrm{S}=$ entrada de $\mathrm{CO}_{2} ; 1=$ frasco para a amostra conectado ao frasco com solução saturada de cloreto de cálcio utilizada para empurrar a amostra; 2 = medidor do fluxo de gás; 3 = tubo secante com $\mathrm{P}_{2} \mathrm{O}_{5} ; 4$ = coluna com carvão ativado, dentro de um frasco Dewar para controle da temperatura; $5=$ interferômetro de gases; A, B, C, D = frascos coletores; 6 = frascos com solução saturada de cloreto de cálcio para ajudar na medida do volume (modificada da referência 5). 
retido, continuando até a última parte, que contém a mistura total. Esse processo de desenvolvimento onde a amostra é continuamente aplicada à coluna é chamado análise frontal.

Um outro pioneiro em análise de gases foi o Dr. Paul Schuftan. Após obter seu doutorado na Universidade de Breslau (nesta época parte de Alemanha, hoje chamada Wroclar, Polônia), em 1922, desenvolveu a sua vida profissional trabalhando nas indústrias de gases, inicialmente com o Gesellschaft für Lindes Eismaschinen em Munich, Alemanha. Seu primeiro projeto foi desenvolver um método para separar diversos gases oriundos da queima seletiva de carvão, mais especifica- mente a fim de obter uma mistura de hidrogênio e nitrogênio para a síntese de amônia ou hidrogênio puro, para a produção de etileno. Após resolver este problema ele se dedicou a desenvolver processos para a separação e identificação de hidrocarbonetos leves. $\mathrm{O}$ método publicado ${ }^{[4]}$ indicou o uso de carvão ativado como fase estacionária, resfriada a $-120{ }^{\circ} \mathrm{C}$ em um banho de etanol congelado, e dióxido de carbono como fase móvel e deslocador (Figura 4). A amostra, uma mistura de gases, foi deslocada do seu recipiente por água e passou por um medidor de vazão e um tubo contendo cloreto de cálcio para secá-la, chegando à coluna. Após a amostra ser transferida à coluna, o fluxo de $\mathrm{CO}_{2}$ para a coluna foi iniciado. Um interferômetro de

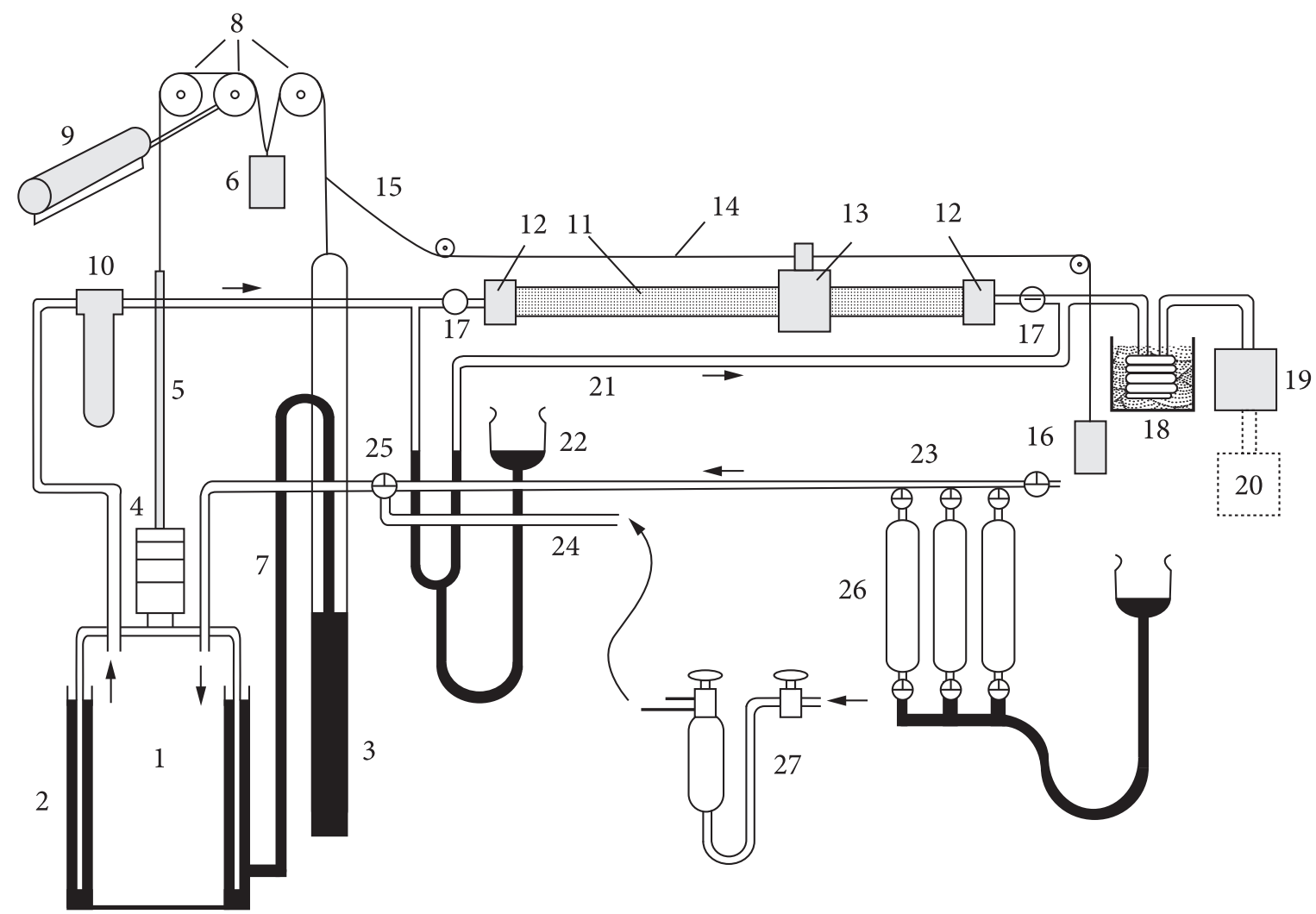

Figura 5 Sistema de Claessens para cromatografia por deslocamento ou análise frontal. Alguns de seus componentes são: 1 = frasco para amostra; 2,3 e 22 = tubos e frasco com mercúrio para o movimento da amostra; $5-9=$ sistema para controlar a pressão no frasco $1 ; 10=$ medidor de fluxo; $11=$ coluna; $12=$ suportes da coluna, resfriado por água; 13 = forno móvel; 14 -16 = controles de movimento do forno; $17=$ torneiras de duas vias; 18 = espiral para resfriar os vapores que saem da coluna; 19 = detector por condutividade térnica; 20 = posição para um detector por densidade de gás; 23, 24, 26, 27 = injetores para diferentes tipos de amostra; 25 = torneira de três vias (modificada da referência 6). 
gases foi empregado como detector. O lado de referência do interferômetro foi alimentado com dióxido de carbono puro e os gases deslocados da coluna pelo $\mathrm{CO}_{2}$ passavam ao lado da amostra. Com a temperatura da coluna a $-120^{\circ} \mathrm{C}$, os componentes inorgânicos saíram do sistema primeiro, sem ser retidos. Depois, duas frações eram coleta-

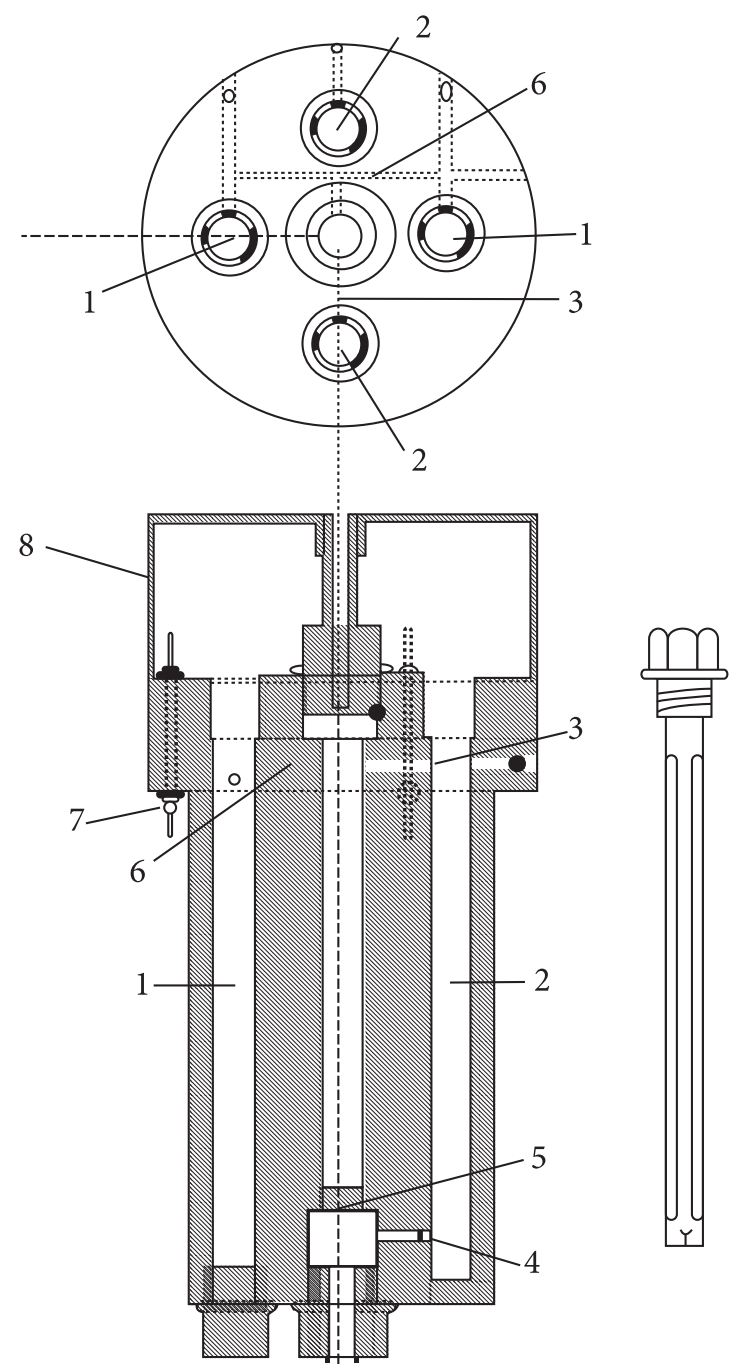

Figura 6 Detector por condutividade térmica desenvolvido por Claessens. Os componentes são: 1 = tubo para gás de referência, contendo um fio PT $(115 \times 0,05 \mathrm{~mm}) ; 2$ = tubo para gás contendo a amostra, contendo um fio PT (115 × 0,05 mm); $3,4=$ conexões do tubo central para os tubos 2 ; $5=$ filtro poroso; 6 = saídas de tubos 1 e $2 ; 7=$ conexão dos fios de PT para a ponte de Wheatstone; 8 = tampa protector. $O$ tubo na direta representa uma detalhe dos tubos 1 e 2 (modificada da referência 6). das separadamente, metano e etileno. $\mathrm{O}$ frasco de resfriamento era removido e etano era coletado à temperatura ambiente. Para a quarta fração, os hidrocarbonetos com três ou mais carbonos eram coletados após aquecimento da coluna a $200{ }^{\circ} \mathrm{C}$. Uma análise consumia ao redor de quatro horas. Os conteúdos dos fracos coletores eram determinados por reações químicas especificas, que identificavam os diferentes gases.

Contribuições importantes no entendimento dos processos de análise frontal e de deslocamento para a determinação de misturas de gases foram feitas por Stig Claesson, nos laboratórios do prof. Arne Tiselius na Universidade de Uppsala, na Suécia. Com uma parte do seu projeto de tese de doutorado defendido em 1946 e publicado em inglês em uma revista sueca ${ }^{[6]}$, Claessen construiu um sistema (Figura 5), com uma coluna $(400 \times 5 \mathrm{~mm})$ recheada com carvão ativado, aquecida por um forno móvel, um detector por condutividade térmica de desenho próprio (Figura 6) acoplado a uma ponte de Wheatstone e um registrador. A injeção da amostra (gasosa ou líquida) foi por deslocamento do reservatório com mercúrio. Quando a

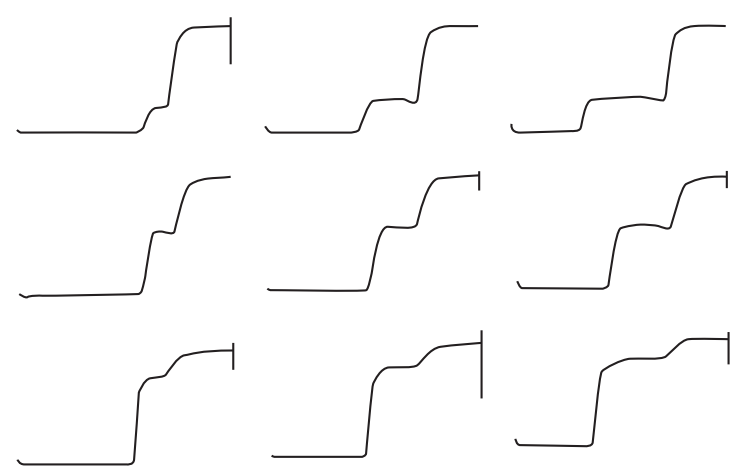

Figura 7 Cromatogramas de Claessens mostrando - deslocamento de alguns hidrocarbonetos. Fase estacionária: Carboraffiln Höganäs $I_{3}$ (um carvão ativado em pó). Deslocador: acetato de etila. Primeira fileira: n-pentano; segunda fileira: n-hexano; terceira fileira: $n$-heptano. Observar que as alturas se repetem dentre de uma fileira e são proporcionais à quantidade da substância injetada (modificada da referência 6). 
análise frontal foi empregada, a coluna foi aquecida apropriadamente e os componentes que saíram passavam pelo detector. Para deslocamento, o reservatório foi recheado com a substância deslocadora, sendo o reservatório aquecido quando necessário para permitir a transferência da substância deslocadora à coluna. Em ambos os casos, o sinal do detector foi registrado. A Figura 7 mostra cromatogramas obtidos no modo de deslocamento de amostras de hidrocarbonetos com vapor de acetato de etila. Esse sistema era muito complicado e, mesmo fornecendo uma quantidade impressionante de dados, após o término da tese não foi mais utilizado.

Em 1946, um professor de química inorgânica da Universidade de Oxford, Inglaterra, Courtenay S. G. Phillips, se interessou pela separação de gases inorgânicos e hidrocarbonetos leves e decidiu realizar experimentos empregando o processo cromatográfico em fase gasosa. Ele decidiu utilizar o método relatado por Claessens, de desenvolvimento por deslocamento, e construiu um sistema simples com uma coluna de carvão ativado, um detector por

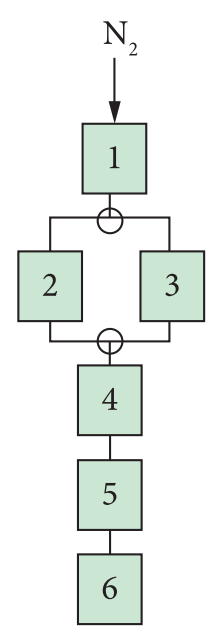

Figura 8 Diagrama de blocos do sistema cromatográfico de Phillips, onde $1=$ controlador de vazão; 2 = frasco da amostra; 3 = frasco do deslocador; 4 = coluna recheada com carvão ativado; $5=$ detector por condutividade térmica; $6=$ coletor de frações (modificada da referência 8). condutividade térmica e um coletor de frações. A Figura 8 indica um diagrama em blocos de seu sistema e a Figura 9 mostra sua coluna. Ele utilizou um fluxo de nitrogênio para empurrar a amostra até a coluna e, depois, mudando a direção do fluxo de nitrogênio, para empurrar o deslocador à coluna. Nitrogênio também foi o gás de referência para o detector. Phillips apresentou seus primeiros resultados em um simpósio sobre análises cromatográficas da Faraday Society da Grã Bretanha, em 1949, e detalhou-os em dois trabalhos publicados em $1952^{[7]}$ e $1953^{[8]}$. A Figura 10 ilustra um dos seus cromatogramas.

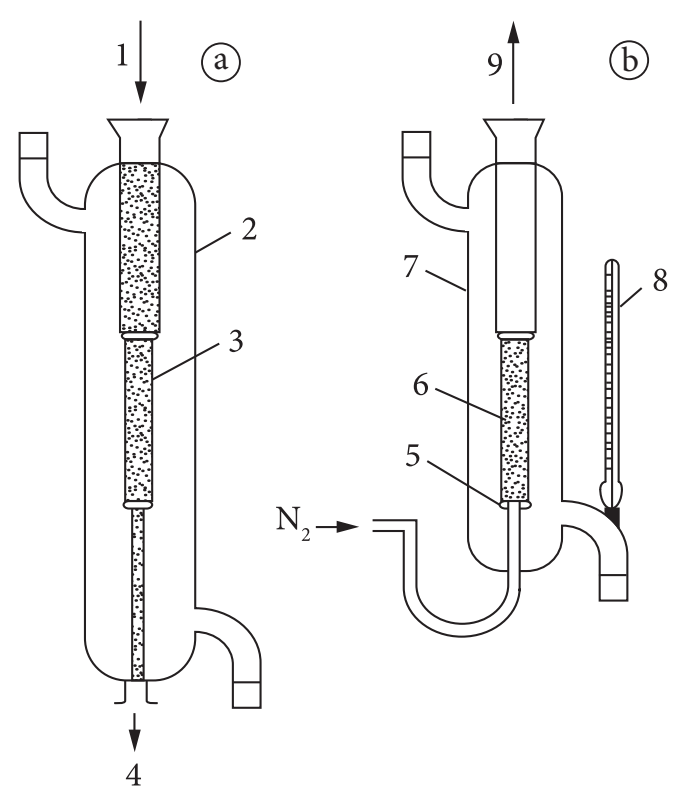

Figura 9 Colunas para cromatografia gás-solido com desenvolvimento por deslocamento, utilizadas por Phillips. a) = coluna de separação; b) = coluna para saturação da fase móvel/deslocador; 1 = entrada da amostra e deslocador em fase móvel; 2 = condensador para a circulação de fluido de aquecimento; 3 = coluna em três segmentos, cada um com comprimento de $10 \mathrm{~cm}$. Os diâmetros foram 16, 8 e 2 mm; 4 = saída para o detector por condutividade térmica e o coletor de frações; $5=$ disco de vidro sinterizado; 6 = líquido deslocador; 7 = condensador para controlar a temperatura; $8=$ termômetro; 9 = saída da fase móvel (nitrogênio) contendo deslocador (modificada da referência 8). 


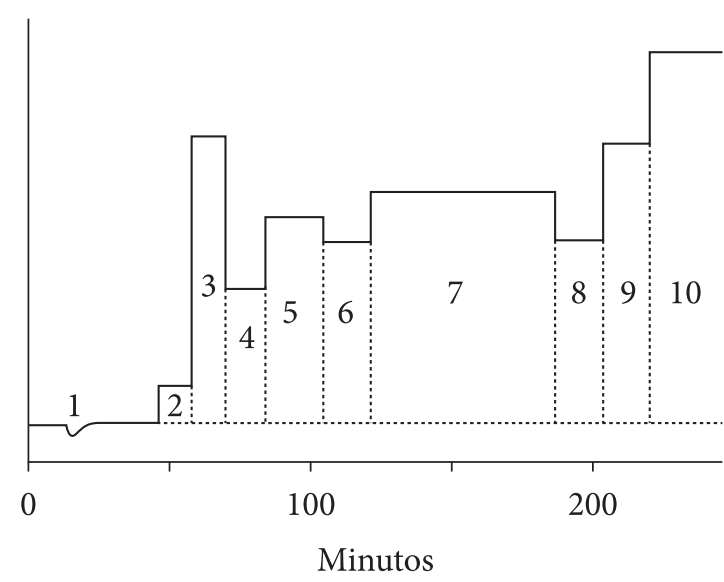

Figura 10 Cromatograma de Phillips utilizando desenvolvimento por deslocamento identificação dos compostos: 1 = água; 2 = éter dietílico; 3 = clorofórmio; 4 = acetato de etila; 5 = tiofeno; 6 = dioxano; $7=$ piridena; 8 = acetato de butila; 9 = diclorobezeno; 10 = bromobemzeno (deslocador) (modificada da referência 8).

Nesses dois trabalhos de Phillips e colaboradores, os autores compararam a eluição por deslocamento com a eluição com eluente, sendo este último o processo mais utilizado em cromatografia gás-sólido nas décadas subsequentes. No próximo capítulo pretende-se discorrer sobre os pioneiros nessa modalidade de cromatografia gás-sólido.

\section{Referências}

1. Wintermeyer U. Historical Review. In: Unger KK, editor. Packings and Stationary Phases in Chromatographic Techniques. New York: Marcel Dekker, 1990.

2. Ramsey W. A determination of the amounts of neon and helium in atmospheric air. Proceedings of the Royal Society of London. Series A, Containing Papers of a Mathematical and Physical Character. 1905; 76:111.

3. Berl E, Schmidt O. Über die Anreicherung und Reindarstellung von Gasgemischen. Zeitschrift für Angewandte Chemie 1923; 36:247. http://dx.doi. org/10.1002/ange.19230363703

4. Schuftan P. Gasanalyse in der Technik. Leipzig: Hirzel Verlag; 1931.

5. Arnold G, Berezkin VG, Ettre LS. Paul Schuftan and the early development of gas-adsorption chromatography. Journal of High Resolution Chromatography \& Chromatography Communications 1985; 8:651. http:// dx.doi.org/10.1002/jhrc.1240081003

6. Claessen, S. Studies on adsorption and adsorption analysis with special reference to homologous series. Arkiv för Kemi, Mineralogi och Geologi 1946: 23:1.

7. Griffiths J, James D, Phillips C. Gas chromatography. Analyst 1952; 77:879.

8. James DH, Phillips CSG. The chromatography of gases and vapours. Journal of the Chemical Society 1953; 1600. http://dx.doi.org/10.1039/ jr9530001600 